Promising Practice

\title{
Bringing Ethics Review Home to Cowichan: Indigenizing Ethics Review in British Columbia, Canada
}

\author{
Cowichan Tribes
}

A R T I C L E IN F O

Keywords:

Indigenous

First Nations

Research

Ethics

Decolonization

Preterm birth

https://doi.org/10.32799/ijih.v16i2.33099

\section{A UTHOR IN F O}

\begin{abstract}
A B S T R A C T
Cowichan Tribes' territory, located in the Cowichan Valley on Vancouver Island, British Columbia, Canada, is experiencing an alarmingly high rate of preterm births compared to the national average of Indigenous Peoples in Canada. In response, and in partnership with the First Nations Health Authority (FNHA), Cowichan Tribes is in the first year of a 3-year study to investigate causes. Cowichan Tribes' Elders and community members are guiding the study to ensure it follows Cowichan Tribes' research processes and to support selfdetermination in research. Furthermore, as a way to enhance reconciliation, Elders and community members guided an on-site ethics review on Cowichan Tribes territory. This article outlines the collaborative, in-person research ethics review process that Cowichan Tribes, Island Health, and FNHA completed on August 21, 2019. The purpose of this article is to provide suggestions other First Nations could use when conducting a research ethics review, and to explain how this process aligns with the principles of ownership, control, access, and possession $\left(\mathrm{OCAP}^{\circledR}\right)$, the United Nations Declaration on the Rights of Indigenous Peoples, the Truth and Reconciliation Commission of Canada, and above all, the Cowichan snuw'uy'ulh (teachings from Elders).
\end{abstract}

Cowichan Tribes, Duncan, British Columbia, Canada. All inquiries can be directed to 250-746-6184 or Derek Thompson, general.manager@cowichantribes.com 


\section{Glossary and Abbreviations}

BC: British Columbia (a province in Canada).

BoR: Board of Record; the research ethics board that holds responsibility for making the final decision regarding ethical approval and oversight for a study when there are multiple boards involved.

FNHA: First Nations Health Authority; a health authority that is responsible for providing, managing, and funding health care for First Nations people across BC.

FNHA's seven directives: Directives given to FNHA by First Nations in BC as fundamental standards for guiding their work.

Island Health: A regional health authority responsible for providing publicly funded health care service delivery on Vancouver Island, the islands in the Salish Sea and the Johnstone Strait, and the mainland communities north of Powell River and south of Rivers Inlet in BC.

Nation-led ethics review process: The process within Cowichan Tribes for granting research ethics approval. The process includes traditional ceremony, dance, song, gifts, and sharing a meal and recognizes existing community processes and protocols for reviewing activities in the Cowichan Tribes community.

OCAP: Standing for ownership, control, access, and possession, $\mathrm{OCAP}^{\circledR}$ is a registered trademark of the First Nations Information Governance Centre (FNIGC; https://fnigc.ca/ocap-training/). This set of principles is used to establish the ways in which First Nations data and cultural knowledge is collected, protected, used, and shared.

Preterm birth: Babies born before 37 weeks' gestation.

Provisos: Conditions attached to the granting of ethics approval that are deemed to be relevant by the Research Ethics Board (REB).

RAC: Research Advisory Committee comprised of researchers and Cowichan community members who are mothers with the lived experience of having a term or preterm infant, along with community Elders. The intention of the RAC guiding the study is to ensure that there is a strong presence of community representation in decision-making.

REB: Research Ethics Board; an institutional committee that reviews proposed research to ensure it is ethically sound.

Research Ethics British Columbia: a collaboration and network between regional health authorities and research institutions that supports a provincial, harmonized system for research ethics review of studies involving more than one BC institution.

RISe: Research Information System; an online research administration tool that allows researchers and administrators to manage and track applications online through to approval, certification, and awarding of funds.

Snuw'uy'ulh: Teachings from Cowichan Elders (see Appendix).

SOP: Standard operating procedure, which defined and outlined the manner in which this alternative ethics review process would occur. 
TRC: Truth and Reconciliation Commission of Canada. The TRC was responsible for sharing the truth about the residential school system by documenting stories of all those affected. In 2015, the commission also published a report with 94 Calls to Action to help guide First Nations, Inuit, and Métis Peoples and Canadians in a process of truth and healing, leading toward reconciliation.

Ts'ewulhtun Health Centre: On-reserve health centre located in the Cowichan Valley (city of Duncan, BC) that is responsible for providing health services to the Cowichan community.

UNDRIP: United Nations Declaration on the Rights of Indigenous Peoples, adopted by the United Nations in September 2007 to outline, in a clear and thorough way, the rights of Indigenous Peoples around the world.

\section{Acknowledgements}

We would like to acknowledge the Cowichan Sul'hween (Elders) and community members that participated in the ethics review and the planning of the study. This process would not be possible without their input. We would also like to thank the reviewers and staff from Island Health and First Nations Health Authority. We extend our appreciation for the financial support from the Vancouver Foundation for the study "Far Too Many Preterm Births in Cowichan Tribes: Generating Knowledge to Inform Service Delivery and Strengthen Motherhood Journeys." We also extend special gratitude to the Manager of Research Ethics and Compliance at Island Health for ongoing and authentic commitment to reconciliatory practices.

\section{Introduction}

This article is written from the Cowichan Tribes' perspective and the primary intended audience is other First Nations. The purpose of the manuscript is to provide a description of a process which other First Nations may consider when conducting research ethics review, and to explain how this process aligns with existing policies and the Cowichan snuw'uy'ulh (teachings from Elders). As one component of the developing Cowichan Tribes research ethics process, and in accordance with existing community protocol, this manuscript was reviewed by Cowichan Tribes leadership and approved for publication via a Band Council Resolution from Chief and Council. Furthermore, the research team requested a Band Council Resolution to maintain transparency and accountability while developing internal ethics review capacity.

With over 5,000 community members, Cowichan Tribes is the largest First Nations band in the province of British Columbia (BC), Canada. Cowichan Tribes is often approached by outside researchers; however, the study described here is an internal project. In 2018, community health nurses noted extremely high rates of preterm births in Cowichan territory through their routine review of annual reports from Cowichan Tribes' electronic charting system. Subsequently, staff at Ts'ewulhtun Health Centre began an exploratory study partnered with the First Nations Health Authority (FNHA) and funded by the Vancouver Foundation. This grant supports a community-led, participatory action study that aims to bring healthy birth back to the 
Cowichan Peoples. As well, a Research Advisory Committee (RAC) made up of Cowichan Elders and mothers with lived experience of term or preterm birth are guiding the project. Both of these aspects of the study design aim to reflect the snuw'uy'ulh of the family is the heart of life (Appendix; Cowichan Tribes, 2020, p. 2).

Ethical review of research in BC typically involves submitting an ethics application to a Research Ethics Board (REB; Research Ethics BC, 2016). Institutions such as universities and health authorities have REBs that are responsible for protecting human participants in research. Paradoxically, these institutions have historically harmed Indigenous Peoples, and have not represented Indigenous worldviews (Meijer Drees, 2010; Mosby, 2013; Sterritt \& Dufresne, 2018), nor acknowledged existing community processes or community-level ethical issues.

To generate self-determination in ethics review, and to honour the snuw'uy'ulh of respect the rights of one another (Appendix; Cowichan Tribes, 2020, p. 2) we were fortunate to embark on a new process for Cowichan Tribes and our local REB of bringing ethics review home to Cowichan territory. On August 21, 2019, Cowichan Tribes hosted an in-person ethics review on Cowichan territory. This event supported Indigenous self-determination by aligning ethics review with the principles of OCAP ${ }^{1},{ }^{1}$ the United Nations Declaration on the Rights of Indigenous Peoples (UNDRIP; United Nations, 2007), the Truth and Reconciliation Commission of Canada (TRC, 2015), FNHA's seven directives (FNHA, n.d.), and the Cowichan snuw'uy'ulh.

This paper documents our Nation-led ethics review that is a departure from traditional academic or other research ethics review with Indigenous Peoples. The overall objective of this paper is to document a milestone in our ongoing Nation-led research ethics process. The Nationled research ethics process is built on existing processes and protocols within Cowichan Tribes and aspires to facilitate co-learning between First Nations, such as Cowichan Tribes, and research ethics institutions, such as a Health REB.

\section{Methods}

To support self-determination in research, the RAC invited Health REB members from Island Health and an ethics advisor from FNHA to Cowichan territory to complete a collaborative, in-person ethics review. In order to do this, FNHA, Cowichan Tribes, and Island Health partnered to develop the methods for completing this review process. These methods included cultural ceremony, oral presentations, and the development of three written documents to guide the process.

\section{Pre-Review}

It was imperative that we ensured self-determination throughout the research process. To communicate our Nation-led processes with the REB, Cowichan Tribes and Island Health collaborated to develop three documents: (a) a standard operating procedure (SOP), (b) a proposal for the alternative process, and (c) official minutes for the review. Island Health took

\footnotetext{
${ }^{1}$ Standing for ownership, control, access, and possession, $\mathrm{OCAP}^{\circledR}$ is a registered trademark of the First Nations Information Governance Centre (FNIGC; https://fnigc.ca/ocap-training/).
} 
official minutes to document the review proceedings and provide a record for accountability and auditing purposes. The proposal outlined that Cowichan Tribes, Island Health, and FNHA should be represented at the in-person review. Island Health was the Board of Record (BoR), which is the main ethics board for a study where multiple ethics boards are involved (Research Ethics BC, 2016). Island Health's role is to grant a Certificate of Approval, making Cowichan Tribes eligible for research funding. Finally, the proposal stated that Cowichan Tribes and Island Health would collaboratively write the administrative SOP to guide the entire process. The SOP formalized how our Nation-led ethics process would operate.

The SOP operationalized the Nation-led ethics review process by providing a framework for a collaborative full board ethics review for multi-jurisdictional research involving two Research Ethics BC partners (Island Health, FNHA). As well, the SOP placed the primary review for ethical issues within the Cowichan teachings and guiding principles, as outlined in the 2015 Cowichan Tribes Research Review Protocol document. This was the first time ceremony was included in a research ethics review process for Cowichan Tribes. As such, the written SOP ensured self-determination for Cowichan Tribes, as well as educated the Health REB about community ethical processes. The SOP outlined that the research team would complete the ethics application and upload it to an online Research Information System (RISe), then the BoR would determine the level of risk to participants, and all involved parties would follow the guidelines from Research Ethics BC (2016). Prior to the review, the Cowichan Elders and mothers in the RAC met with Island Health's Manager of Research Ethics and Compliance to review the ethics application with the goal of building ethics review capacity within Cowichan Tribes. The SOP set an agenda for the ethics review but remained flexible to allow the RAC to determine how the events of the day would unfold. Importantly, all involved parties agreed that Cowichan Tribes would have the first review and final approval of the study, and the BoR would facilitate the ethics review. The implications of having the first review and final approval of the study are outlined in the discussion section below.

\section{Review}

The review opened with a blanketing ceremony, traditional dance, drumming, and song to centre the review in Cowichan traditions. Guests to the Cowichan Tribes territory, including the research team, were blanketed and cedar headbands were placed around their heads. In Cowichan, a blanketing ceremony shows respect for people who have made an important contribution to our community (Cowichan Tribes, n.d.). Following cultural protocols, Elders led the procession outside for ceremonial song and dance from the Cowichan Tzinquaw dancers. Cowichan Elders and members sang, drummed, and danced four traditional songs in front of the blanketed guests. The first song welcomed the group to the territory. The second dance "brushed off" the group with cedar boughs, which is symbolic of clearing obstacles for the work. The third honoured women and mothers, and the closing song was a victory song to ensure the success of the study. The ceremony took place in a centre courtyard between Cowichan Tribes buildings. Approximately 50 staff came outside to bear witness to the ceremony and honour the blanketed attendees.

V OLUME 16 , IS S UE 2, $2021 \bullet 74$ 
The procession returned inside to Chief and Council chambers, where an Elder opened the table with a prayer and the Chair for Cowichan Tribes shared a traditional song and story. A gift was presented as an act of reciprocity and to honour an Elder for his important work in the community. Gifts were also presented to the members of the research team from Cowichan Tribes, as an appreciation for their work to date. Following roundtable introductions, the group shared a meal before they began reviewing the ethics application. The ethics application was first reviewed in small groups of approximately five people with representatives from each organization. Then, the large group reconvened to share feedback. There was rich dialogue and discussion on many topics with everyone in the group providing input. Cowichan Tribes Elders regarded the study as approved after the cultural ceremonies were complete because the review adhered to Cowichan protocols and processes. Island Health then completed a review separate from the in-person review.

\section{Post-Review}

The SOP defined the procedures that would occur post-review. The SOP outlined that after the in-person review, the BoR would upload the provisos from their delegated review to RISe. FNHA's Interim Ethics Review Committee would then conduct their own review, indicating additional provisos and adding them into RISe. The Principal Investigator (lead researcher of the study) would collaborate with the BoR to address all provisos. Once the provisos had been satisfied, the Principal Investigator would receive a Joint Certificate of Ethics Approval. Importantly, methods for dealing with ongoing ethics review, as well as evaluation of the alternative ethics review process, were embedded into the SOP.

\section{Relationship}

The core research team is made up of the project Lead (Principal Investigator), the Special Projects Research Advisor, and the Special Projects Research Worker, who coordinate the study and are Cowichan Tribes staff. The core team took the lead in writing this article with editing assistance from three research partners from FNHA. Study team members also include Island Health's Medical Health and Research Liaison Officers. The study team is guided by RAC members who are Cowichan Tribes Elders and Cowichan Tribes mothers with lived experience having a term or preterm infant. One of the Elders reviewed this article prior to publication. The core team and Cowichan Tribes leadership decided that publishing the manuscript as a group author aligns with the aim of increasing self-determination by honouring Indigenous knowledge and authorship in traditionally colonial spaces.

In the spring of 2018, the project Lead reached out to FNHA for data on preterm birth rates for other First Nation communities. No data were available, but FNHA invited the project Lead to FNHA's monthly meeting on maternal health. Through these meetings, the project Lead met the Co-Lead, who is a Clinical Nurse Specialist for maternal and child health; as well as another Co-Investigator who, at the time, was an analyst for FNHA.

The initial group connected with the Medical Health and Research Liaison Officers for the area, who joined the RAC and offered a letter of support. Another analyst at FNHA was later 
added to the RAC for additional support with the project. The project Lead received support for the study from the Cowichan Tribes Health Director and approval for the study from Chief and Council in the form of a Band Council Resolution. The Medical Health and Research Liaison Officers connected the project Lead with the Manager of Research Ethics and Compliance, who facilitated the in-person review process and collaborated with the study team to develop written procedures to guide the ethics review.

\section{Limitations}

This article is not a complete description of the institutional processes required to complete a research ethics review in a new way. The purpose of this specific manuscript is to provide a First Nations lens to the process. Since at the time of writing the study had not yet received a Certificate of Approval from Island Health, it was felt to be premature to co-author a manuscript with Island Health. The historic mistrust between Indigenous populations and government and academic researchers (Schnarch, 2004) was another factor that influenced the lens of this manuscript; in respect for self-determination and ownership with research, it was important for our First Nation's perspective to be heard. We anticipate future articles will be written to describe the actions and perspective of the Health REB within this research ethics review process. As well, balancing community approval and Research Ethics BC approval warrants further discussion but is outside of the scope of this work.

Human and financial resources, as well as time, are limitations to completing an inperson ethics review on Cowichan Tribes territory. Having an in-person review had associated financial, time, and human resource costs that would not have been present with the usual electronic process of submitting ethics applications directly via a university or health authority's online system. For example, we provided honoraria to Elders and community members to compensate them for their input into the review. As well, planning and organizing the review event took up human resources from within the study team, community members, and staff from all participating organizations. Finally, receiving final ethics approval was protracted because conducting an alternative process involved more parties and different processes than per usual. Given that research ethics approval is legally tied to the processes of Western institutions, our Nation-led process to attain community-level research ethics approval was only possible due to community resources. We recognize that our process is associated with substantial resource considerations. Therefore, specific funding for Nation-led ethics review that respects existing community protocols and processes should be considered when applying for funding.

\section{Discussion}

Bringing ethical review home to a Nation's territory supports Indigenous selfdetermination because it allows Indigenous Peoples to have greater control over decisions about ourselves, while honouring traditional forms of Indigenous governance and decision-making. Historically, the ethics review process was developed to protect vulnerable people from being taken advantage of due to power imbalances between researcher and participant (Panel on Research Ethics, 2018). However, representatives from the community who are meant to be 
"protected" are rarely included in this process, resulting in a paternalistic approach to protecting vulnerable people (Ball \& Janyst, 2008). Supporting Indigenous self-determination is not achievable when Indigenous Peoples are excluded from decisions about our communities. As well, a paternalistic context makes it difficult to honour the TRC's (2015) Calls to Action and UNDRIP (United Nations, 2007), both of which centre their values on the concept of selfdetermination. Using these documents as a framework, as well as the Cowichan Elders' teachings (snuw'uy'ulh) and FNHA's seven directives, this ethics review process was intended to find ways to challenge present health and academic systems and demonstrate a different approach that supports self-determination. The following sections will describe how leveraging approval authority in ethics review, land, language, relationships, cultural traditions, and Indigenous knowledge supports self-determination.

\section{Approval Authority}

Historically, Indigenous Peoples were excluded from decision-making related to First Nations communities. Granting Cowichan Tribes the final approval authority in an ethics review supports self-determination by devolving systemic power and control of Western research institutions to First Nations Peoples and reflects the Cowichan snuw'uy'ulh of respect the rights of one another (Appendix; Cowichan Tribes, 2020, p. 2). The in-person review facilitated active self-determination, whereby Cowichan leaders took back the control regarding decisions about our people. Granting final approval authority to support self-determination is also supported by FNHA's seven directives. Directive 2, Increase First Nations decision-making and control (FNHA, n.d.), is demonstrated through the transfer of power from a health authority or university to the Cowichan community, who are then able to influence the research process and approve or decline the study.

Articles 4 and 19 from UNDRIP (United Nations, 2007) support an alternative ethics review process that increases self-determination by granting First Nations final approval authority over research that affects First Nations peoples. Article 4 states: "Indigenous peoples, in exercising their right to self-determination, have the right to autonomy or self-government in matters relating to their internal and local affairs" (United Nations, 2007, p. 8). The SOP states that Cowichan Tribes has the final review of the ethics application for the study, reflecting Cowichan Tribes' right to autonomous self-determination and governance regarding research protocols and approvals.

Of note, the initial review is the first of several stages of the ethics process. At the time of writing, final ethical approval has not been granted. Nonetheless, we have built ongoing evaluation into our SOP to validate this Nation-led ethics review process, as well as methods for addressing ethics renewals and amendments. However, this article is concerned primarily with the initial stage of the review. We plan to write further papers about the process of ongoing validation of the review. 


\section{Land and Relationship}

By hosting the review on Cowichan territory and integrating community voice in the process, we were able to increase self-determination, aligning with the snuw'uy'ulh of learn from one another and respect the rights of one another (Appendix; Cowichan Tribes, 2020, p. 2). The review gathered people who historically would not collaborate in the same room, creating the opportunity to learn from one another. If we conducted a typical ethics review, this opportunity would not have arisen, as the work would have occurred off site by reviewers who may not have interacted with the Cowichan community in the past. By hosting an in-person review, Cowichan Tribes set the stage for the review and centred the work in culture. Moreover, outsiders had the opportunity to listen to and learn about Cowichan Peoples' priorities and protocols, such as ceremonial dance, song, gifts, and sharing a meal. Centring these protocols and ensuring that we started the day with protocol set our Nation-led process apart from conventional ethics review. Therefore, outsiders were exposed to the information necessary to be able to respect the rights of others. Respecting First Nations' rights is integral to selfdetermination.

Hosting a review on Cowichan territory responds to FNHA's Directive 4, Foster meaningful collaboration and partnership (FNHA, n.d.), which includes fostering collaboration in research and reporting at all levels. Undertaking the ethics review on Cowichan territory allowed Cowichan Elders and community members, and staff at Cowichan Tribes, FNHA, and Island Health, to meet in person and build meaningful relationships. Meeting in person also created space for community traditions, such as witnessing, which allowed for community ownership of the study. The opportunity to build relationships supported the collaborative decision-making necessary for Cowichan Tribes to determine how research on, with, and about Cowichan Tribes should be completed.

Finally, hosting the review on Cowichan territory created a shift of power: Cowichan Tribes community members were on traditional Cowichan Tribes territory and the research personnel were visitors to an unfamiliar process. Hosting ethics review on Cowichan Tribes territory ensured that community values were respected. This shift in power complies with UNDRIP, whereby "Indigenous Peoples have the right to the lands, territories and resources which they have traditionally owned, occupied or otherwise used or acquired" (United Nations, 2007, p. 19). Since the project is concerned with Cowichan Peoples and will occur on Cowichan territory, the ethics review should occur on Cowichan territory as well.

\section{Cultural Activities}

The Cowichan snuw'uy'ulh of honour the Elders (Cowichan Tribes, 2020, p. 2) is aligned with including cultural activities in the review. Cowichan Elders initiated, planned, organized, and facilitated the cultural activities for the event. Centring the event on Cowichan teachings and traditions prioritizes the Cowichan Elders' input into the research and supports self-determination. While the Tri-Council Policy Statement of Canada (Panel on Research Ethics, 2018) still requires the research project to have an ethics certificate from a REB, the inperson review created the space for Cowichan Tribes members to review the study using a 
cultural lens. The blanketing ceremony and ceremonial dancing and songs were conducted to give respect to Cowichan Tribes' culture and our ancestors, who are viewed as a higher approval authority than any modern ethics board. A Cowichan Elder taking part in the ethics review reflected, "This is the only approval we need. As far as we are concerned, we are approved now. We are family" (personal communication, August 21, 2019).

Article 27 of UNDRIP (United Nations, 2007, p. 20) also explains that "states shall establish and implement, in conjunction with Indigenous peoples concerned, a fair, independent, impartial, open and transparent process, giving due recognition to Indigenous peoples' laws, traditions, customs" and that "Indigenous Peoples shall have the right to participate in this process." Finally, designing the ethics review around cultural traditions respects "Indigenous Peoples' right to self-determination in spiritual matters, including the right to practise, develop, and teach their own spiritual and religious traditions, customs, and ceremonies" (TRC, 2015, p. 201), which is consistent with Article 12:1 of UNDRIP (United Nations, 2007).

\section{Conclusion}

In sum, a Nation-led research ethics review process that respects existing protocols and processes supports self-determination in research. The idea of completing a Nation-led ethics review process, guided by community, was borne out of a need to increase Cowichan Tribes' decision-making and control over research about Cowichan community members. Granting approval authority to Cowichan Tribes, leveraging land and relationship, and incorporating cultural ceremony support self-determination by subverting the existing and historical power relationships between researchers and Indigenous Peoples. Moreover, by participating in this process, Island Health, FNHA, and Cowichan Tribes are working toward finding new ways to build research capacity within First Nations communities in BC and beyond. Nation-led ethics review was particularly relevant to this specific project because the project is held within Cowichan Tribes. We feel the inclusive in-person ethics review, complete with a strong community presence and rich culture and ceremony, was a positive experience that aligns with the values of the Cowichan Peoples, as described in the snuw'uy'ulh of respect the rights of one another, learn from one another, and honour the Elders. Furthermore, the in-person review aligns with FNHA's seven directives, the TRC, OCAP, and UNDRIP, and ultimately supports Indigenous self-determination. Significantly, this in-person review process promotes a shift in narrative so that community-based research occurs in collaboration with Indigenous Peoples, not on Indigenous Peoples.

This article reflects only the initial stage of a long journey toward self-determination throughout the research process. The next step of our process will include validation on a regular basis to ensure the research continues to move forward in a good way, determined by Cowichan Tribes. This paper is the first of many to come where we document our process, especially the validation of our Nation-led research ethics process. This peer-reviewed article is intended to reach both the Indigenous community and academic audiences. We also intend to document our process and co-learning in traditional ways that align with Cowichan Tribes, including oral accounts.

V OLUME 16 , ISSUE 2, $2021 \cdot 79$ 


\section{References}

Ball, J., \& Janyst, P. (2008). Enacting research ethics in partnerships with Indigenous communities in Canada: "Do it in a good way." Journal of Empirical Research on Human Research Ethics, 3(2), 33-51. https://doi.org/10.1525/jer.2008.3.2.33

Cowichan Tribes. (n.d.). Traditions we still practice today. https://www.cowichantribes.com/about-cowichan-tribes/history/traditions-we-stillpractice-today/

Cowichan Tribes. (2020). Cowichan Tribes annual report 2019-2020. https://cowichantribes.com/application/files/9816/0635/0142/CowichanTribesAnnualReport-2019-20-FINAL-mobile.pdf

First Nations Health Authority. (n.d.). Directives. http://www.fnha.ca/about/fnhaoverview/directives

Meijer Drees, L. (2010). The Nanaimo and Charles Camsell Indian hospitals: First Nations' narratives of health care, 1945 to 1965. Histoire sociale/Social History, 43(85), 165-191. https://doi.org/10.1353/his.2010.0002

Mosby, I. (2013). Administering colonial science: Nutrition research and human biomedical experimentation in Aboriginal communities and residential schools, 1942-1952. Histoire sociale/Social History, 46(91), 145-172. https://muse.jhu.edu/article/512043/summary

Panel on Research Ethics. (2018). Tri-council policy statement: Ethical conduct for research involving humans. Canadian Institutes of Health Research, Natural Sciences and Engineering Research Council of Canada, and Social Sciences and Humanities Research Council of Canada. https://ethics.gc.ca/eng/policy-politique_tcps2-eptc2_2018.html

Research Ethics British Columbia. (2016). Guidance for harmonized ethics review of multijurisdictional studies. BC Ethics Harmonization Initiative. https://researchethicsbc.ca/wpcontent/uploads/2018/08/7.-REBC-guidance-harmonized-ethics-29-aug-2016.pdf

Schnarch, B. (2004). Ownership, control, access, and possession (OCAP) or self-determination applied to research: A critical analysis of contemporary First Nations research and some options for First Nations communities. Journal of Aboriginal Health (now International Journal of Indigenous Health), 1(1), 80-95. https://doi.org/10.3138/ijih.v1i1.28934

Sterritt, A., \& Dufresne, M. (2018, February 1). "Canadians would be shocked”: Survivors, lawyers describe treatment at Nanaimo Indian Hospital. CBC News. https://www.cbc.ca/news/canada/british-columbia/canadians-would-be-shockedsurvivors-lawyers-describe-treatment-at-nanaimo-indian-hospital-1.4513476

Truth and Reconciliation Commission of Canada. (2015). Honouring the truth, reconciling for the future: Summary of the final report of the Truth and Reconciliation Commission of Canada. http://www.trc.ca/assets/pdf/Honouring_the_Truth_Reconciling_for_the_Future_July_23 _2015.pdf

United Nations. (2007). United Nations Declaration on the Rights of Indigenous Peoples. https://www.un.org/development/desa/indigenouspeoples/wpcontent/uploads/sites/19/2018/11/UNDRIP_E_web.pdf 


\section{Appendix}

\section{Cowichan Snuw'uy'ulh (Teachings from Elders) in English and Traditional Hul'q'umi'num Language, Where Available}

\begin{tabular}{|l|l|}
\hline Hul'q'umi'num language & English language \\
\hline $\begin{array}{l}\text { Mukw' tu shhw'a'luqw'a' 'o' tth'ele's tu } \\
\text { shhwuli }\end{array}$ & The family is the heart of life \\
\hline $\begin{array}{l}\text { Hiiye'yutul tst 'u to' mukw' stem 'i'u tun'a } \\
\text { tumuhw }\end{array}$ & $\begin{array}{l}\text { Everything in nature is part of our family- } \\
\text { we are all relatives }\end{array}$ \\
\hline Stsielhstuhw tu S-ul'hween & Honour the Elders \\
\hline Tl'i'to' mukw' mustimuhw & Each person is important \\
\hline Hwial'asmut tu tumuhw & $\begin{array}{l}\text { Take care of the Earth and take only what you } \\
\text { need }\end{array}$ \\
\hline Hwial'asmut ch tun's-ye'lh & Take care of your health \\
\hline Yath ch 'o' lhq'il' & Be positive \\
\hline 'Iyusstuhw tun'a skweyul & Enjoy today \\
\hline Thuluqtul ch 'u kwthun'kwunmun & Share what you have \\
\hline Ts 'iiyulh ch 'u tuni's-aamustham-mut & Give thanks for what you have been given \\
\hline- & Learn from one another \\
\hline- & Respect your neighbours \\
\hline- & $\begin{array}{l}\text { Help one another and work together for the } \\
\text { good of all }\end{array}$ \\
\hline- & Be honest and truthful in all you do and say \\
\hline- & Do the best you can do, be the best you can be \\
\hline- & Live in harmony with nature \\
\hline- & Take responsibility for your actions \\
\hline- & All things are connected \\
\hline- & Respect the rights of one another \\
\hline- & Respect your leaders and their decisions \\
\hline
\end{tabular}

Note. For some of the teachings, the Hul'q'umi'num writing is still being formalized and approved (indicated here with a dash). Adapted from Cowichan Tribes Annual Report 20192020 (https://cowichantribes.com/application/files/9816/0635/0142/CowichanTribesAnnualReport-2019-20-FINAL-mobile.pdf). Copyright 2020 by Cowichan Tribes. 